\title{
RANCANG BANGUN SISTEM INFORMASI RUMAH TRADISIONAL BALI BERDASARKAN ASTA KOSALA-KOSALI BERBASIS WEB
}

\author{
Oka Sudana ${ }^{1,}$ Agus Suryadana*2, $^{* 2}$ Agung Bayupati $^{3}$ \\ ${ }^{1,2,3}$ Program Studi Teknologi Informasi, Fakultas Teknik, Universitas Udayana, Bali, Indonesia \\ Email: 1'agungokas@unud.ac.id, ${ }^{2}$ agus.suryadana1996@gmail.com, ${ }^{3}$ bayupati@it.unud.ac.id \\ *Penulis Korespondensi
}

(Naskah masuk: 13 Februari 2019, diterima untuk diterbitkan: 07 Oktober 2020)

\begin{abstract}
Abstrak
Rumah tradisional Bali adalah bangunan yang memiliki ciri khas khusus yang difungsikan sebagai hunian yang merupakan salah satu cerminan kebudayaan yang tumbuh dan berkembang di Bali. Panduan pembangunan Rumah Tradisional Bali tertuang dalam Lontar Asta Kosala-Kosali dan Asta Bumi. Modernisasi berdampak dalam perubahan bentuk dan kebutuhan bangunan perumahan yang mengakibatkan penerapan Arsitektur Tradisional Bali semakin berkurang dan tidak memperhatikan nilai filosofis yang seharusnya, sehingga dikembangkan sistem informasi sebagai media pengenalan dan panduan penerapan Arsitektur Tradisional Bali. Sistem yang dikembangkan disesuaikan dengan konsep Asta Kosala-Kosali dan Asta Bumi. Sistem Informasi Rumah Tradisional Bali menyajikan berbagai macam informasi dan fitur mengenai penerapan Asta KosalaKosali dan Asta Bumi dalam Rumah Tradisional Bali yang dihadirkan dalam bentuk pemodelan 2 dimensi dan 3 dimensi. Sistem dapat memudahkan dalam pemahaman filosofi, aturan, tata cara, tata letak, dan tata bangunan Rumah Tradisional Bali serta mampu menjadi media pelestarian warisan budaya Bali khususnya dibidang arsitektur. Persentase tingkat kepuasan pengguna terhadap sistem rata-rata sebesar $87.24 \%$.
\end{abstract}

Kata kunci: Rumah Tradisional Bali, Arsitektur tradisional, Asta Kosala-Kosali, Sistem Informasi

\section{DESIGN OF BALI TRADITIONAL HOME INFORMATION SYSTEM BASED ON WEB-BASED ASTA KOSALA-KOSALI}

\begin{abstract}
A traditional Balinese house is a building that has special characteristics that function as a residence which is a reflection of the culture that grew and developed in Bali. Guide to building Balinese Traditional Houses contained in Lontar Asta Kosala-Kosali and Asta Bumi. Modernization has an impact on changes in the shape and needs of residential buildings which have resulted in the application of Balinese Traditional Architecture diminishing and not paying attention to philosophical values that should be, so that information systems are developed as a medium of introduction and guidance on the application of Balinese Traditional Architecture. The system developed was adapted to the concept of Asta Kosala-Kosali and Asta Bumi. The Traditional Balinese House Information System presents various kinds of information and features regarding the application of Asta Kosala-Kosali and Asta Bumi in Balinese Traditional Houses which are presented in the form of 2dimensional and 3-dimensional modeling. The system is expected to facilitate the understanding of the philosophy, rules, procedures, layout, and structure of traditional Balinese Houses as well as being able to become a medium for preserving the Balinese cultural heritage, especially in the field of architecture. Percentage of satisfaction level of users of the system by an average of $87.24 \%$.
\end{abstract}

Keywords: Traditional Balinese Houses, Traditional Architecture, Asta Kosala-Kosali, Information Systems

\section{PENDAHULUAN}

Rumah tradisional adalah bangunan yang memiliki ciri khas khusus yang difungsikan sebagai hunian oleh suatu suku bangsa. Rumah tradisional merupakan salah satu cerminan kebudayaan yang tumbuh dan berkembang di sebuah suku/masyarakat pada daerah tertentu. Salah satu rumah tradisional yang ada di Indonesia adalah Rumah Tradisional
Bali. Masyarakat Hindu Bali percaya, bangunan memiliki jiwa bhuana agung (makrokosmik) sedangkan manusia yang menjaga bangunan adalah bagian dari bhuana alit (mikrokosmik). Manusia (mikrokosmik) dan bangunan yang ditempati harus harmonis, untuk mendapatkan keseimbangan antara kedua dunia, maka membangun bangunan harus sesuai dengan prosedur yang ditulis dalam Lontar Asta Kosala-Kosali (Damayanti, 2017). Asta 
Kosala-Kosali dan Asta Bumi merupakan sebuah tata cara, tata letak, dan tata bangunan untuk bangunan tempat tinggal serta bangunan tempat suci yang ada di Bali yang sesuai dengan landasan filosofis, etis, dan ritual dengan memperhatikan konsepsi perwujudan, pemilihan lahan, hari baik membangun rumah, serta pelaksanaan yadnya. Perkembangan zaman berdampak pada perubahan kebutuhan masyarakat yang berdampak dalam kebutuhan bangunan perumahan yang sesuai dengan era modern, mengakibatkan Arsitektur Tradisional Bali mengalami perubahan bentuk dan kebutuhan bangunan perumahan yang mengakibatkan penerapan Arsitektur Tradisional Bali semakin berkurang dan tidak memperhatikan nilai filosofis yang seharusnya. Perubahan yang terjadi antara lain tidak memperhatikan tata ruang dalam pembangunan rumah, dimana terkesan rungan dalam rumah seperti kamar tidur, dapur maupun kamar mandi ditempatkan sesuai keinginan pemilik rumah tanpa memperhatian pola tata ruang Sanga Mandala. Pembangunan rumah modern juga tidak mematuhi satuan ukur tradisional Bali yaitu sikut dengan pertimbangan luas tanah yang terbatas meskipun sesuanguhnya sikut dapat disesuaikan dengan ukuran tanah yang dimiliki serta masih banyak lagi aturan tradisional yang tidak dipakai karena arsitektur modern dianggap lebih mudah dan efisien. Pertumbuhan properti baru di Bali dikhawatirkan menggeser semangat lokalitas dan jati diri arsitektur lokal, sehingga menyebabkan hilangnya kesadaran masyarakat Bali dalam memahami pembuatan Rumah Tradisional Bali. Modernisasi juga berdampak terhadap generasi muda Bali yang mulai melupakan warisan budaya tradisional karena masih kurangnya media pembelajaran budaya yang modern dan lebih menarik. Media pembelajaran budaya tradisional hanya terpaku pada buku dan media cetak lainnya, sehingga sangat diperlukan media pembelajaran yang lebih modern seperti memanfaatkan perangkat komputer dan smartphone agar penyampain informasi lebih efisien dan praktis (Sudana, Wulan and Wirdiani, 2016). Penelitian mengenai Rumah Tradisional Bali sebelumnya, antara lain penggunaan teknologi Augmented Reality pada sistem Rumah Tradisional Bali, kajian visual bangunan Dapur Tradisional Bali, penerapan konsep hulu-teben pada Permukiman Tradisional Bali, pembuatan game sebagai media pengenalan merajan, dan penelitian tentang perkembangan bentuk angkul-angkul (pintu pekarangan) pada Rumah Tradisional Bali. Sistem Rumah Tradisional Bali dalam bentuk Augmented Reality Book menggunakan media buku biasa yang dilengkapi teknologi Augmented Reality. Buku dapat menampilkan objek Rumah Tradisional Bali dalam bentuk 2 dimensi dan dapat menampilkan objek Rumah Tradisional Bali dalam 3 dimensi dengan menggunakan aplikasi Augmented Reality Viewer pada smartphone (Wiartika et al., 2013). Kajian visual tentang salah satu bangunan tradisional dalam perumahan khas Bali yaitu dapur dengan studi kasus yang dilakukan di Kecamatan Kubu Karangasem, Bali untuk mengetahui struktur bangunan, satuan ukur yang digunakan serta fungsi dari bagian-bagian dapur tradisional (Intaran, Koriawan and Witari, 2015). Penerapan konsep hulu-teben dalam pengaturan tata letak bangunan menggunakan konsep hulu-teben atau yang biasa dimaksud kajakelod (utara-timur) sebagai simbol gunung di utara dan laut di selatan yang menempatkan bangunan sesuai fungsinya yang sakral dan suci di zona hulu dan bangunan dengan tingkatan rendah di zona teben (Adiputra, Wiyono and Sarwadi, 2016). Game Mrajan Bali bertujuan untuk mengedukasi dan memperkenalkan pengguna mengenai Bangunan Tradisional Bali yaitu merajan, dibangun berbasis android, sehingga dapat menjadi media pembelajaran yang menyenangkan (Wirawan, Buana and Wiranatha, 2017). Kajian perubahan arsitektur angkul-angkul membahas faktor yang mempengaruhi perubahan bentuk seiring dengan perkembangan dan penyesuaian zaman hingga fungsionalitas bangunan angkul-angkul di era modern seperti sekarang (Wijaya, 2017). Penelitian terdahulu menunjukkan pentingnya pengenalan Bangunan Tradisional Bali termasuk Asitektur Tradisional Bali.

Berdasarkan beberapa penelitian sebelumnya, belum ada penelitian mengenai cara penerapan aturan dalam Asta Kosala-Kosali dan Asta Bumi pada sebuah pada Rumah Tradisional Bali. Sistem informasi yang dirancang dilengkapi dengan fitur perhitungan serta pemodelan yang disajikan secara 2 dimensi dan 3 dimensi. Sistem diharapkan dapat memudahkan dalam pemahaman filosofi, aturan, tata cara, tata letak, dan tata bangunan Rumah Tradisional Bali serta mampu menjadi media pelestarian warisan budaya Bali khususnya dibidang arsitektur.

\section{METODE PENELITIAN}

Metode penelitian yang digunakan dalam penelitian Sistem Informasi Asta Kosala-Kosali dan Asta Bumi dalam Arsitektur Rumah Tradisional Bali berbasis web adalah metode waterfall. Alasan menggunakan metode waterfall karena pendekatan dilakukan secara sistematis dalam pembangunan sistem. Tahapan yang dilakukan antara lain analisis kebutuhan, pengumpulan data dengan teknik orservasi lapangan dan wawancara, perancangan sistem, implementasi sistem, pengujian sistem dan evaluasi, analisis kepuasan pengguna.

Tahapan analisis kebutuhan dilakukan penetapan tujuan penelitian dan rencana dalam mencapainya serta kebutuhan apa saja yang diperlukan dalam mencapai tujuan tersebut. Tahapan pengumpulan data dilakukan dengan cara pengumpulan materi, materi yang dikumpulkan didapat dari studi literatur dan wawancara dengan 
narasumber. Studi liteatur yang digunakan diperoleh dari jurnal dan buku terjemahan. Tahapan selanjutnya dilakukan perancangan dan implementasi sistem sesuai dengan gambaran sistem yang direncanakan sebelumnya. Tahapan selanjutnya dilakukan pengujian sistem. Pengujian sistem dilakukan dengan cara menguji sistem bersama dengan narasumber di bidang Arsitektur Tradisional Bali untuk memastikan kesesuaian informasi dan hasil sistem dengan aturan arsitektur yang ada. Tahapan selanjutnya dilakukan analisis kepuasan pengguna terhadap kehadiran dan kinerja sistem yang telah dibuat. Pengukuran kepuasan pengguna dilakukan dengan metode kuisioner dengan melibatkan 50 responden dengan latar belakang pekerjaan dan rentang usia yang beragam.

\subsection{Studi Literatur}

Berikut akan dijabarkan studi literatur dalam penelitian ini, pembahasan dapat dilihat pada subbab berikut (Saputra, Sukarsa and Bayupati, 2017). Sistem informasi selain berfungsi sebagai pendistribusian informasi yang bermanfaat juga dapat menjadi alat yang ampuh dalam peningkatan efektivitas dan efesiensi dalam bisnis proses (Utami, Nugroho and Wijaya, 2018).

\subsubsection{Sistem Informasi}

Sistem informasi merupakan kombinasi teknologi, prosedur kerja, informasi, aktivitas orang yang diorganisasikan untuk mencapai suatu tujuan dalam organisasi dan pelaku bisnis.

\subsubsection{Rumah Tradisional Bali}

Rumah Tradisional Bali selain digunakan sebagai hunian bagi masyarakatnya juga merupakan salah satu cerminan kebudayaan yang tumbuh dan berkembang di sebuah suku/masyarakat. Rumah Tradisional Bali merupakan salah satu rumah tradisional yang ada di Indonesia. Rumah Tradisional Bali adalah kumpulan dari bangunan atau ruangan dengan fungsi yang berbeda dengan ciri khas terdapat halam kosong (natah) dan dikelilingi oleh tembok disegala arah yang disebut (penyengker).

\subsubsection{Asta Kosala Kosali}

Pembangunan Rumah Tradisional Bali harus memperhatikan aspek-aspek yang biasa disebut dengan konsep Tri Hita Karana agar tercipta hubungan yang serasi dan seimbang antara aspek parahyangan, pawongan, dan palemahan. Dalam konteks perumahan, parahyangan dimaksudkan sebagai hubungan antara penghuni rumah (manusia) dengan Tuhan Yang Maha Esa, pawongan adalah hubungan antara sesama penghuni rumah (manusia), dan palemahan dimaksudkan sebagai hubungan antara penghuni sebuah rumah dan lingkungan sekitarnya. Proses membangun Rumah Tradisional Bali membutuhkan waktu yang relatif lama mulai dari proses pengukuran tanah (nyikut karang), ritual mecaru, ritual peletakan landasan (nasarin), proses konstruksi, dan upacara melaspas. Semua proses ini memiliki tujuan agar rumah yang dibangun memberikan manfaat terbaik bagi pemilik dan penghuninya. Pengukuran konstruksi atau tata letak bangunan didasarkan pada aturan Asta KosalaKosali dan Asta Bumi (Suharta, Sudiarta and Astawa, 2017). Asta Kosala-Kosali merupakan landasan dalam pembangunan Rumah Tradisional Bali yang meliputi ukuran bangunan rumah, pepalihan, ornamen hiasan dan sebagainya. Kitab Weda Kalpa menjelaskan bahwa Asta Kosala-Kosali merupakan landasan dasar dalam pembangunan Rumah Tradisional Bali dengan memperhatikan sisi filosofis, etika dan ritual keagamaan yang tumbuh dan berkembang di Bali (Dwijendra, 2008).

\subsubsection{Sikut}

Sikut merupakan satuan ukur dalam arsitektur bangunan tradisional Bali. Berbeda dengan satuan ukur seperti biasanya dalam pembangunan rumah yang menggunakan meter, sentimeter dan lain sebagainya. Arsitektur Tradisional Bali mengguankan satuan ukur bernama sikut yang diambil dari anatomi tubuh seperti jari (a-lengkat), lengan (a-depa), dan kaki (a-tapak), serta ada juga yang menggunakan persepsi berdasarkan kemampuan seseorang untuk menentukan suatu ukuran, contohnya cara mengukur menggunakan pengelihatan terjauh (penelengan) dan cara mengukur menggunakan lemparan terjauh (penimpugan). Setiap pengukuran dengan sikut selalu ditambahkan ukuran ekstra yang dikenal dengan istilah urip (ukuran tambahan dengan makna tertentu) (Parwata, 2011).

\subsubsection{Sanga Mandala}

Arsitektur Tradisional Bali mengenal beberapa konsep pembagian ruang menurut arah mata angina antara lain, konsep kangin-kauh (timur-barat) dan konsep kaja-kelod. Konsep kangin-kauh diadaptasi dari arah sumbu matahari. Arah timur sebagai arah matahari terbit dianggap arah yang suci dan dan dianggap zona utama. Arah barat sebagai tempat matahari terbenam dianggap sebagai zona nista. Konsep kaja-kelod (utara-selatan) diadaptasi berdasarkan arah Gunung Agung di Bali. Arah utara dianggap zona suci atau utama yang melambangkan Gunung Agung. Sedangkan arah selatan dianggap zona nista yang melambangkan laut. Penggabungan antara konsep kangin-kauh dan kaja-kelod tersebut disebut konsep Sanga mandala. Konsep Sanga mandala dalam kebudayaan masyarahat Hindu Bali berasal dari arah penyebaran kekuasaan manifestasi Tuhan dalam tugas-Nya sebagai pengawas alam semesta. Sembilan manifestasi Tuhan tersebut adalah Dewa Wisnu sebagai penguasa arah utara, Dewa Sambhu sebagai penguasa arah timur laut, Dewa Iswara sebagai penguasa arah timur, Dewa Maheswara sebagai penguasa arah tenggara, Dewa Brahma sebagai penguasa arah selatan, Dewa Rudra 
sebagai penguasa arah barat daya, Dewa Mahadewa sebagai penguasa arah barat, Dewa Sangkara sebagai penguasa arah barat laut, dan Dewa Siwa sebagai penguasa arah tengah (Rudiasti, Sudana and Raharja, 2017). Konsep Sanga mandala dijadikan acuan dalam pembagian zona kegiatan dan pembagian tata letak bangunan pada Arsitektur Tradisional Bali. Kegiatan maupun bangunan yang dianggap suci diletakan pada zona utamaning utama. Kegiatan atau bangunan diaggap kotor diletakan di zona nistaning nista, Sedangkan kegiatan atau bangunan lainnya diletakan pada zona madya (natah) (Dwijendra, 2008).

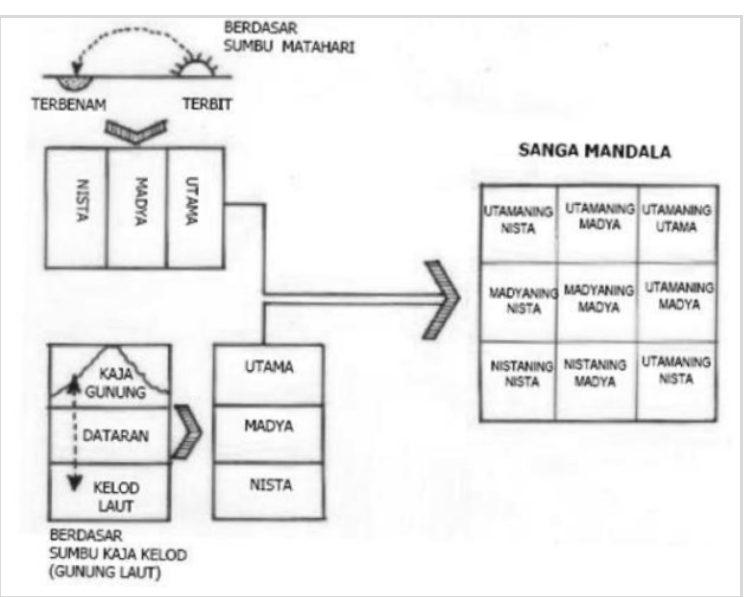

Gambar 1. Konsep Sanga Mandala

\section{PERANCANGAN SISTEM}

Sistem Informasi Rumah Tradisional Bali Berdasarkan Asta Kosala-Kosali berbasis web merupakan sebuah sistem yang memungkinkan untuk mempelajari budaya tradisional Bali dalam bentuk arsitektur bangunan tradisional. Sistem informasi ini dibuat berdasarkan konsep arsitektur tradisional Asta Kosala-Kosali. Fitur yang terdapat dalam sistem antara lain informasi umum mengenai Bangunan Bali dan fungsinya, menentukan arah lahan/rumah, menentukan letak pintu pekarangan rumah (pemedal), menentukan tata letak bangunan dan fitur jenis-jenis sanggah pamerajan. Gambaran umum sistem dapat dilihat pada Gambar 2.

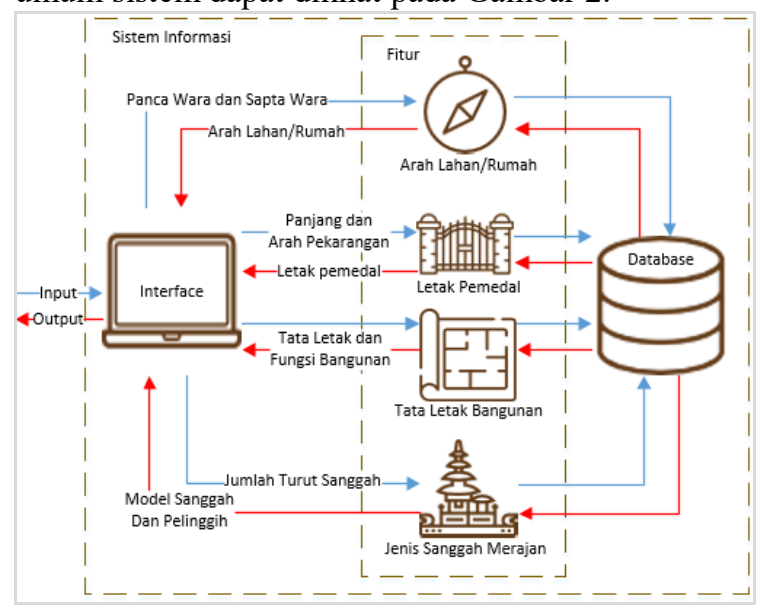

Gambar 2. Gambaran umum sistem

\section{HASIL DAN PEMBAHASAN}

\subsection{Antarmuka Sistem}

Antarmuka Sistem Informasi Rumah Tradisional Bali Berdasarkan Asta Kosala-Kosali berbasis web dapat dilihat pada Gambar 3.

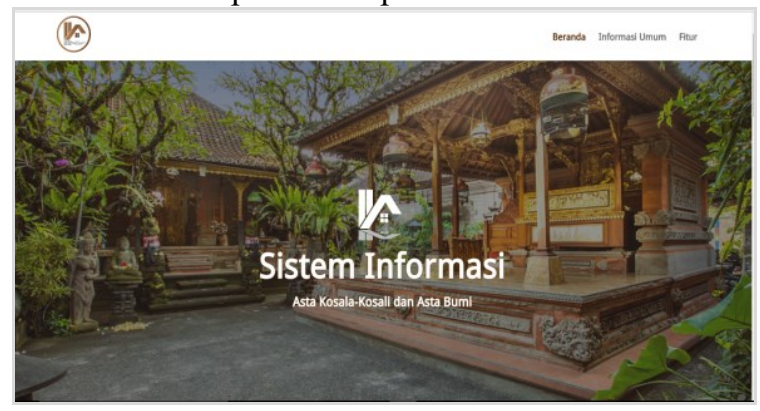

Gambar 3(a). Tampilan beranda sistem

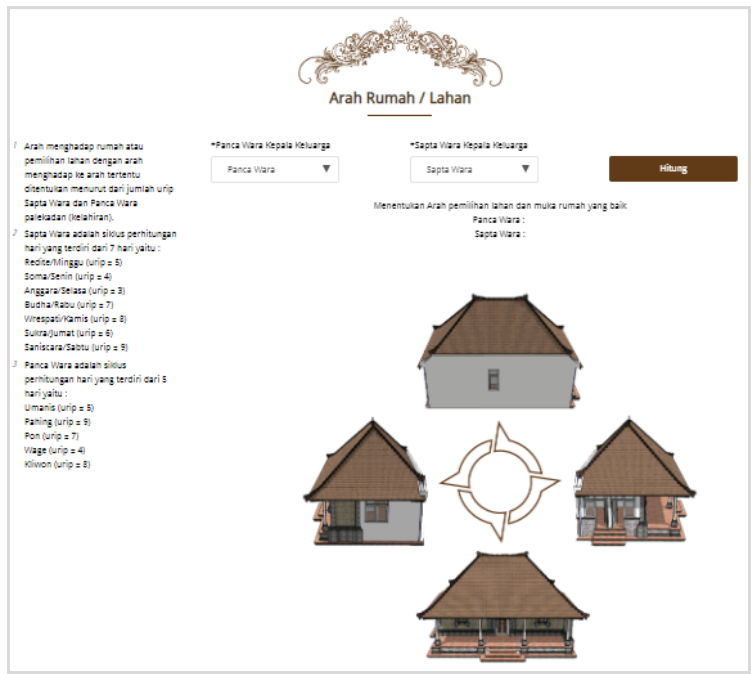

Gambar 3(b). Tampilan fitur menentukan arah rumah/lahan

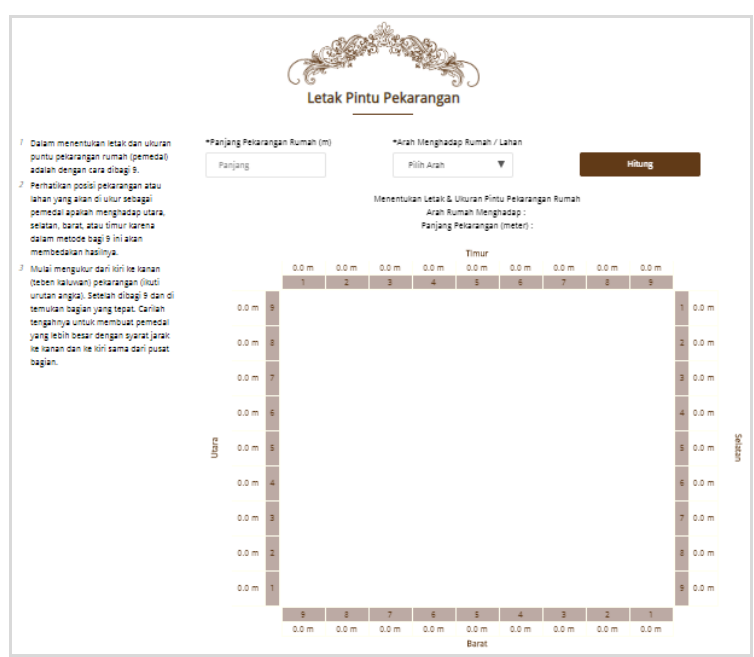

Gambar 3(c). Tampilan fitur menentukan letak pintu pekarangan 


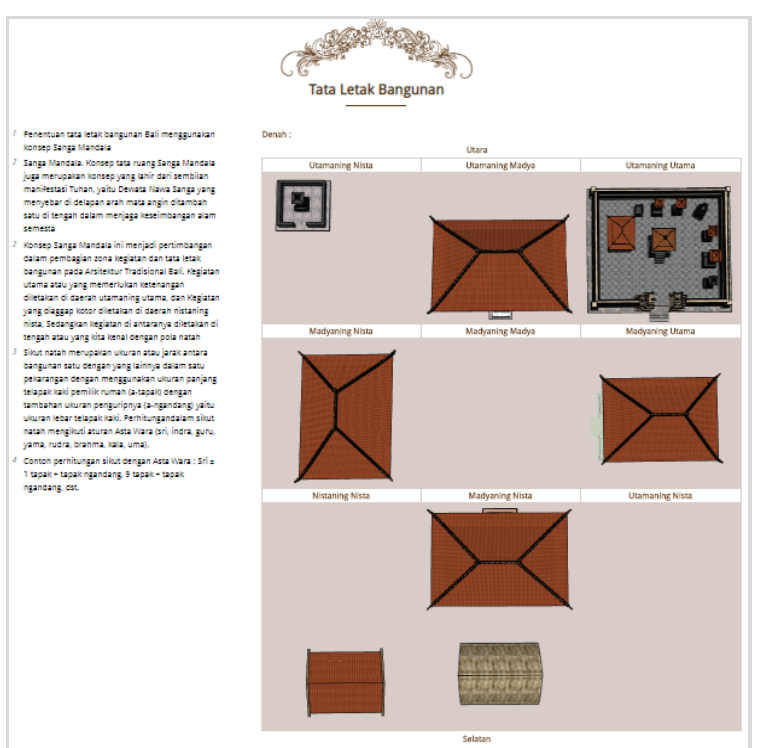

Gambar 3(d). Tampilan fitur tata letak bangunan

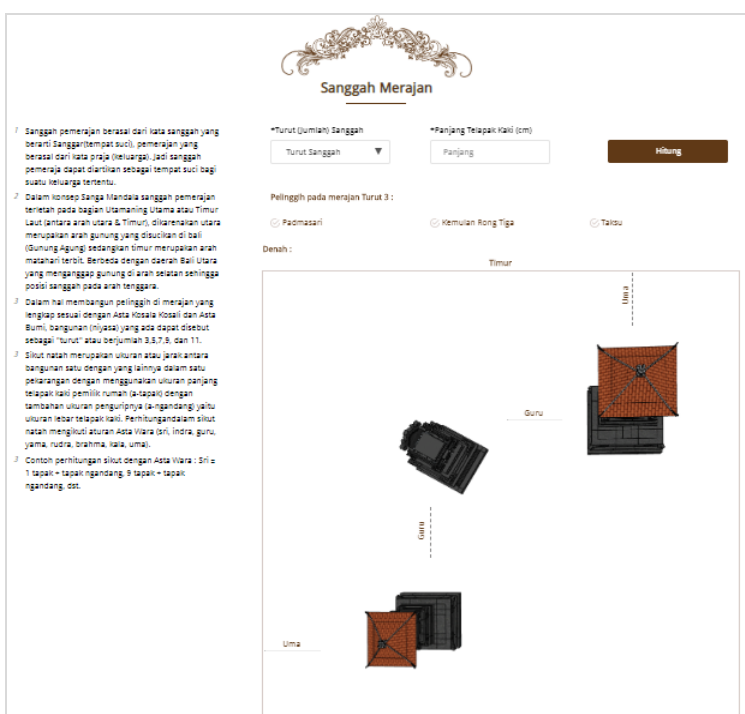

Gambar 3(e). Tampilan fitur sanggah pamerajan

Antarmuka awal pada Sistem Informasi Rumah Tradisional Bali Berdasarkan Asta Kosala-Kosali berbasis web dapat dilihat pada Gambar 3(a). Antarmuka sistem dirancang berbasis web yang dilengkapi berbagai macam informasi mengenai Arsitektur Tradisional Bali serta fitur yang dapat diakses pengguna. Fitur yang dapat diakses dalam sistem yaitu fitur menentukan arah rumah/lahan, fitur menentukan pintu pekarangan, fitur tata letak bangunan dan fitur sanggah pamerajan. Antarmuka fitur menentukan arah rumah/lahan dapat dilihat pada Gambar 3(b), antarmuka fitur menentukan pintu pekarangan dapat dilihat pada Gambar 3(c), antarmuka fitur tata letak bangunan dapat dilihat pada Gambar 3(d) dan antarmuka fitur sanggah pamerajan dapat dilihat pada Gambar 3(e).

\subsection{Fitur Menentukan Arah Rumah/Lahan}

Fitur menentukan arah menghadap lahan/rumah pada Sistem Informasi Rumah Tradisional Bali Berdasarkan Asta Kosala-Kosali berbasis web dapat dilihat pada Gambar 4.

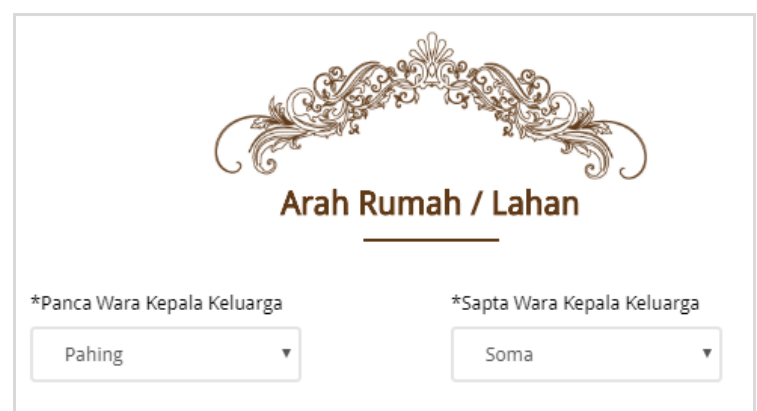

Gambar 4. Uji coba fitur menentukan arah menghadap lahan/rumah

Gambar 4 merupakan tampilan saat memasukkan data Panca Wara dan Sapta Wara. Data Panca Wara yang dimasukkan adalah pahing dan Sapta Wara adalah soma, selanjutnya sistem akan memproses data masukkan tersebut dengan menjumlahkan urip (nilai) dari pahing dan soma, kemudian hasil penjumlahan akan disesuaikan dengan arah menghadap rumah yang sesuai. Hasil dari perhitungan akan ditampilkan berupa arah yang sesuai yang dapat dilihat pada Gambar 6 .

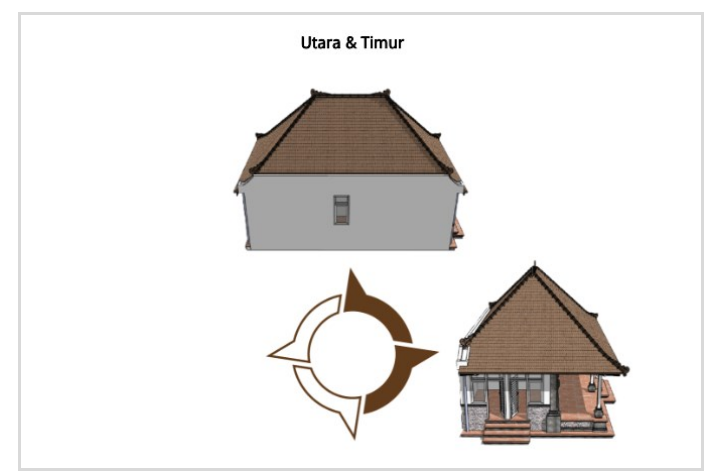

Gambar 5. Hasil Perhitungan Menentukan Arah Menghadap Lahan/Rumah

Gambar 5 merupakan hasil perhitungan dari fitur menentukan arah menghadap lahan/rumah. Hasil ditampilkan berupa arah menghadap rumah yang baik sesuai dengan Panca Wara dan Sapta Wara kelahiran pemilik rumah.

\subsection{Fitur Menentukan Letak Pintu Pekarangan}

Uji coba fitur menentukan letak pintu pekarangan pada Sistem Informasi Rumah Tradisional Bali Berdasarkan Asta Kosala-Kosali berbasis web dapat dilihat pada Gambar 7. 


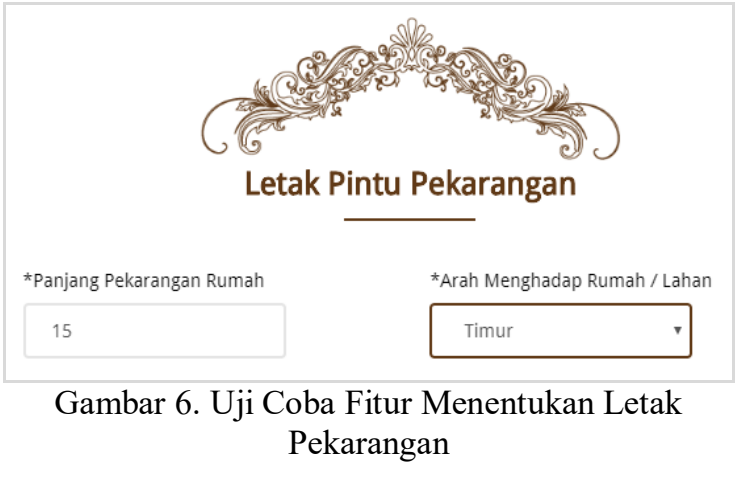

Gambar 6 merupakan tampilan saat memasukkan data panjang pekarangan rumah dan arah menghadap rumah. Data panjang pekarangan yang dimasukkan adalah 15 meter dan arah mengharap pekarangan adalah timur. Selanjutnya hasil perhitungan dapat dilihat pada Gambar 7.

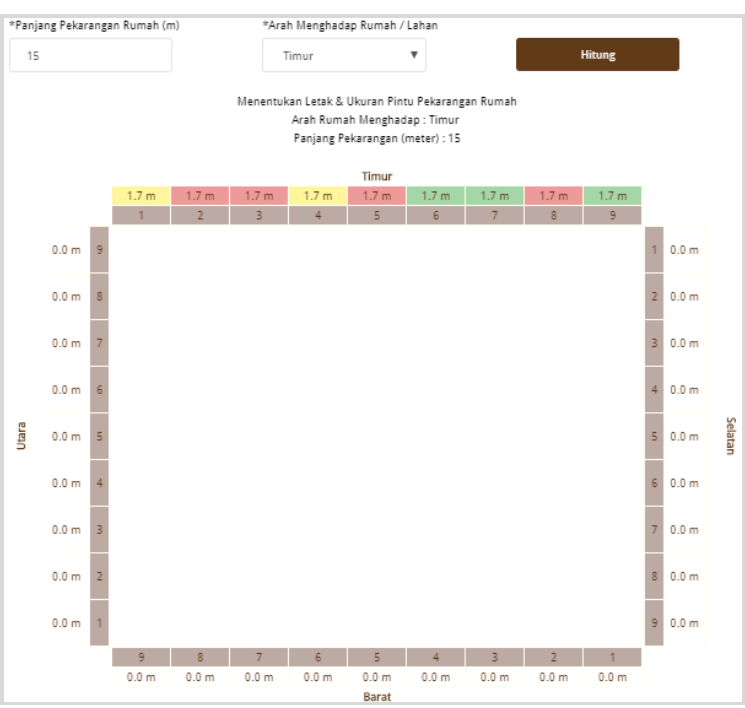

Gambar 7(a). Denah pekarangan hasil perhitungan

1. Maduwe sentana $=$ Memiliki anak (Baik)

2. Sering meweh = sering susah (Tidak baik)

3. Kawon = Tidak baik (Tidak baik)

4. Wikan $=$ Pintar (Baik)

5. Kapaten = Meninggal (Tidak baik)

6. Rahayu = Selamat (Sangat baik)

7. Sugih = Kaya (Sangat baik)

8. Kaceda = Celaka (Tidak baik)

9. Suka = Senang (Sangat baik)

Gambar 7(b). Filosofi baik dan buruk setiap bagian pekarangan

Gambar 7(a) merupakan tampilan hasil perhitungan berupa pemodelan denah pekarangan rumah, dimana pekarangan yang nantinya akan dibangun pintu pekarangan akan dibagi menjadi 9 bagian yang berbeda yang nantinya bagian tersebut akan menjadi tembah dibangunnya pintu pekarangan. Setiap bagian memiliki warna indikator yang menyatakan jika warna hijau maka pintu pekarangan sangat baik jika dibangun di bagian tersebut, warna kuning maka pintu pekarangan baik dibangun pada bangin tersebut dan warna merah maa pintu pekarangan tidak baik dibangun pada bagian tersebut. Setiap bagian juga memiliki filosofi baik buruk tersendiri yang dapat dilihat pada gambar 7(b).

\subsection{Fitur Tata Letak Bangunan}

Fitur tata letak bangunan pada Sistem Informasi Rumah Tradisional Bali Berdasarkan Asta KosalaKosali berbasis web dapat dilihat pada Gambar 8(a) dan Gambar 8(b).
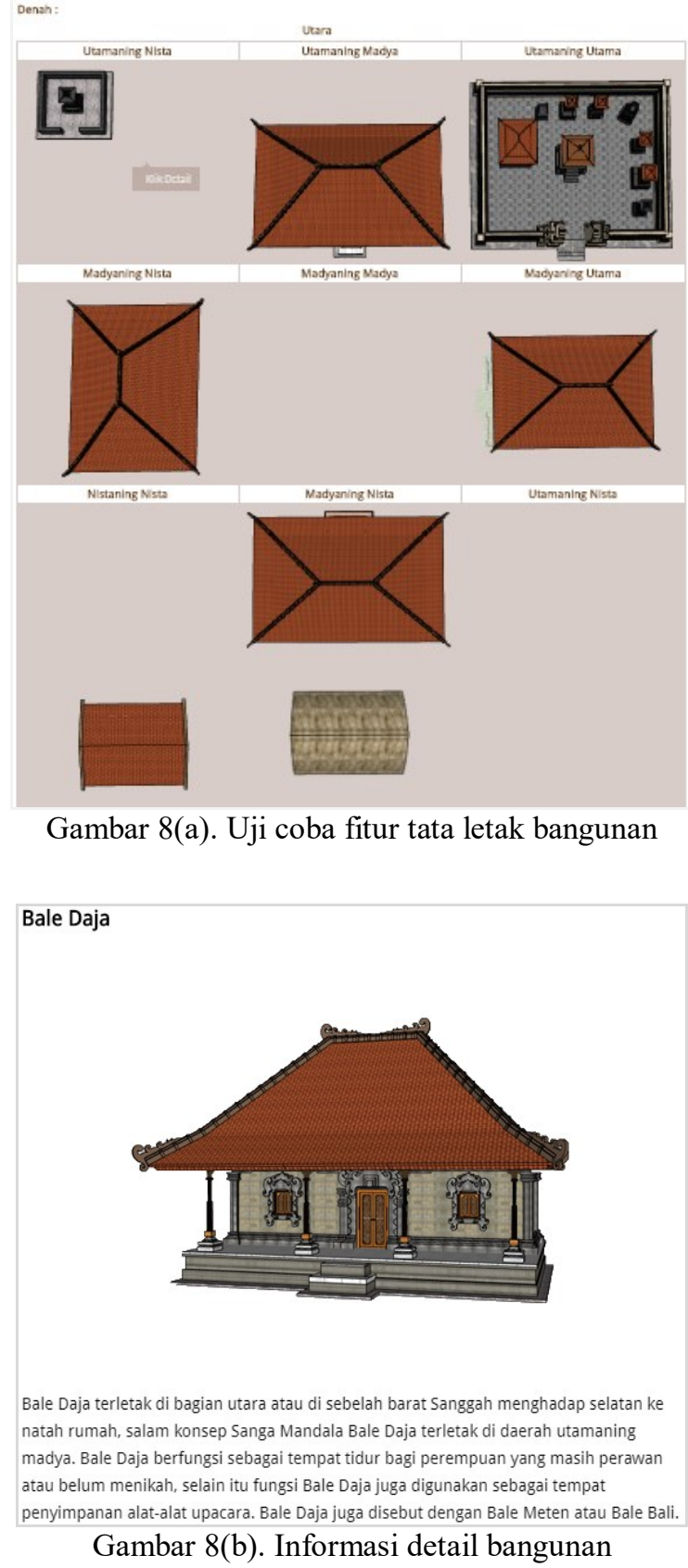

Gambar 8(a) merupakan tampilan awal fitur tata letak bangunan. Informasi detail bangunan tersebut dapat dilihat pada Gambar 8(b) dengan hanya klik pada salah satu bangunan yang diinginkan. Selain pemodelan berupa 2 dimensi terdapat juga 
pemodelan 3 dimensi. Pemodelan 3 dimensi dapat dilihat pada Gambar 9.

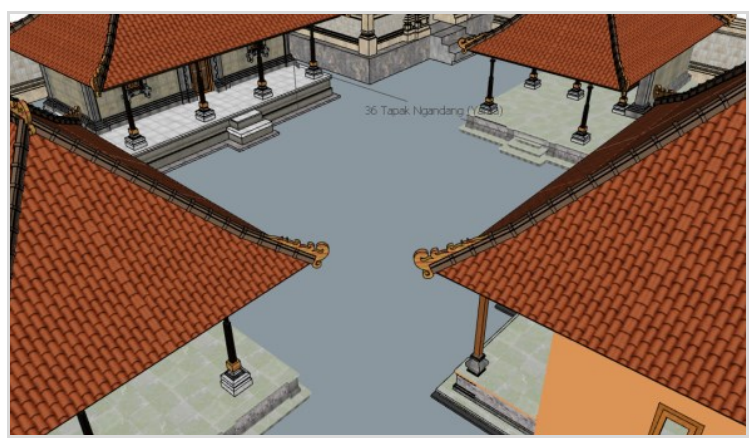

Gambar 9. Pemodelan 3 dimensi rumah bali

Gambar 9 merupakan pemodelan 3 dimensi Rumah Bali dengan tata letak mengikuti konsep Sanga mandala pada pemodelan 3 dimensi terdapat informasi sikut jarak antar bangunan yang ideal menggunakan ukuran tapak (ukuran kaki) pemilik rumah.

\subsection{Fitur Sanggah Merajan}

Fitur sanggah merajan pada Sistem Informasi Rumah Tradisional Bali Berdasarkan Asta KosalaKosali berbasis web dapat dilihat pada Gambar 10.

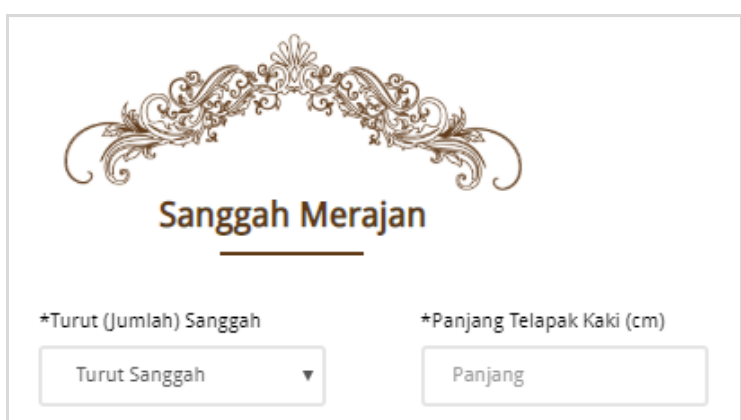

Gambar 10. Uji Coba fitur sanggah merajan

Gambar 10 merupakan tampilan awal fitur tata letak bangunan. Terdapat form input untuk memasukkan jenis sanggah yang diinginkan serta ukuran tapak (telapak kaki) pemilik rumah untuk menentukan jakark antar pelinggih. Jika Jenis sanggah yang dimasukkan adalah sanggah turut 5 dan panjang tapak adalah $30 \mathrm{~cm}$ maka akan tampil hasil pemodelan seperti pada Gambar 11(a) dan Gambar 11(b).

Gambar 11(a) merupakan tampilan model sanggah sesuai dengan jenis turut yang masukkan yaitu turut 5 dan panjang tapak $30 \mathrm{~cm}$. Gambar 11(b) menampilkan informasi detail pelinggih yang terdapat dalam sanggah turut 5 yang ditampilkan hanya dengan klik pada bangunan pada denah. Selain informasi mengenai bangunan sanggah terdapat juga ukuran yang menampilkan ukuran ideal untuk sanggah dan jarak ideal antar bangunan. Selain pemodelan berupa 2 dimensi terdapat juga pemodelan 3 dimensi sanggah merajan. Pemodelan 3 dimensi dapat dilihat pada Gambar 12.

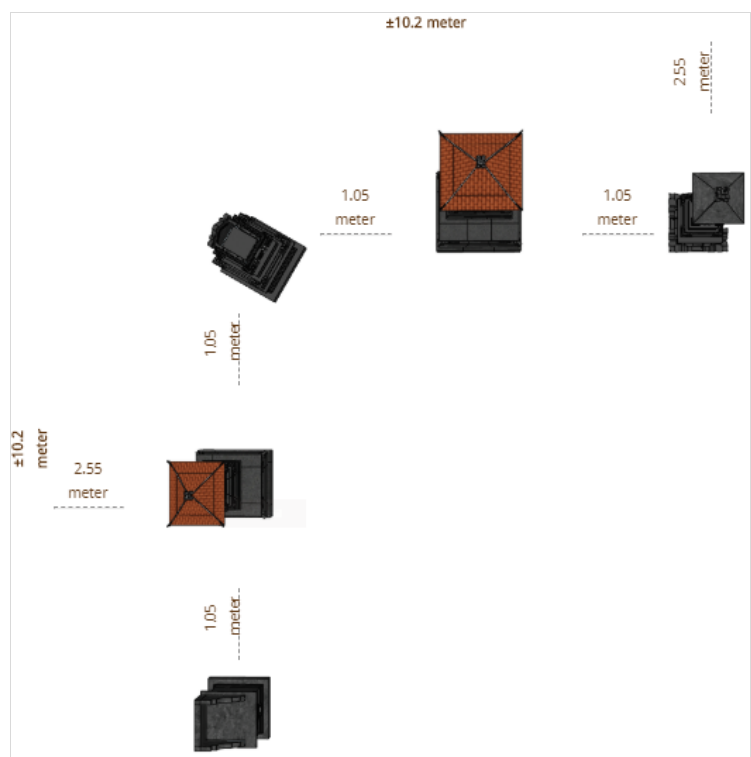

Gambar 11(a). Tampilan denah sanggah Padmasari

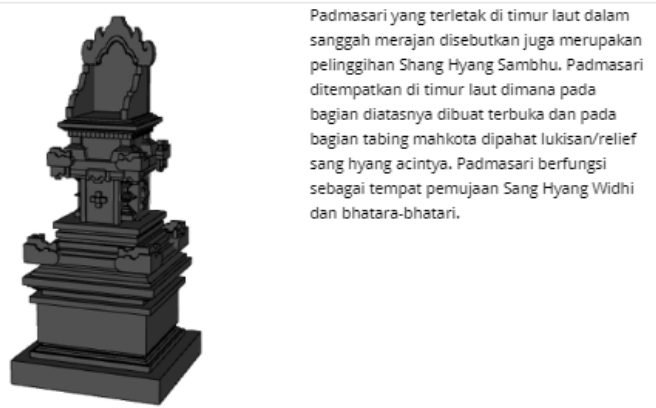

Gambar 11(b). Informasi detail sanggah

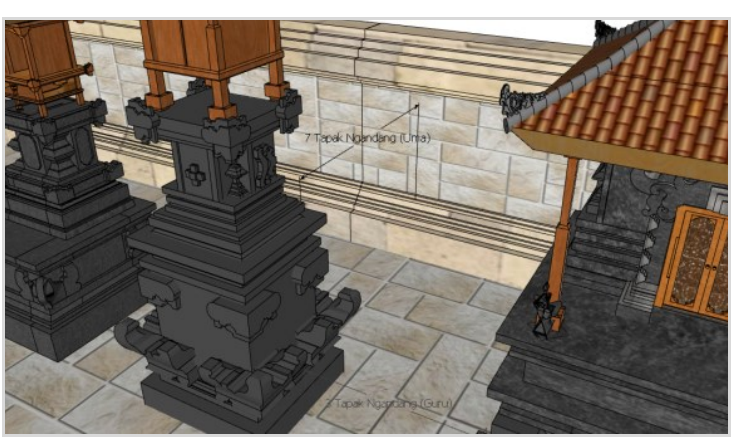

Gambar 12. Pemodelan 3 dimensi sanggah merajan

Gambar 12 merupakan pemodelan 3 dimensi sanggah merajan, pada pemodelan 3 dimensi terdapat informasi sikut jarak antar bangunan yang ideal menggunakan ukuran tapak (ukuran kaki) pemilik rumah.

\subsection{Analisis Hasil Penelitian}

Penelitian sebelumnya yang merancang sebuah buku dengan teknologi augmented reality sebagai media pengenalan model rumah rumah tradisional bali berdasarkan Asta Kosala-Kosali (Wiartika et al., 
2013) belum mampu membantu dalam pengaplikasian aturan Asta Kosala-Kosali dalam sistem. Penelitian Sistem Informasi Asta KosalaKosali dan Asta Bumi dalam Arsitektur Rumah Tradisional Bali berbasis web, perhitungan dan pengaplikasian aturan Asta Kosala-Kosali dapat dilakukan serta dilengkapi dengan pemodelan 2 dimensi dan 3 dimensi dan satuan ukur yang ideal, sehingga mempermudah dalam pemahaman dan pengaplikasian. Penelitian lainnya yang mengembangkan sebuah game dengan jenis puzzle drag and drop pembangunan merajan sebagai sarana edukasi dan pengenalan bangunan tradisional Bali khususnya merajan yang dirancang dalam bentuk game berbasis android (Wirawan, Buana and Wiranatha, 2017) yang bertujuan sebagai sarana hiburan dan hanya menyajikan informasi dengan cakupan lebih kecil yaitu merajan. Penelitian Sistem Informasi Asta Kosala-Kosali dan Asta Bumi dalam Arsitektur Rumah Tradisional Bali berbasis web. Sistem dibuat dalam bentuk sistem informasi berbasis web yang lebih efektif dan efisien serta lengkap dalam penyampaian informasi seluruh bangunan Rumah Tradisional Bali dan dapat diakses secara mudah dan real-time.

\subsection{Analisa Kepuasan Pengguna}

Pengukuran kepuasan pengguna atau user experience pada suatu sistem dapat diukur dalam berbagai metode salah satunya dengan metode pengumpulan data kuisioner. Kuisioner adalah alat yang murah dan sangat efisien untuk mencapai ukuran kuantitatif user experience $(U X)$ suatu sistem (Schrepp, Hinderks and Thomaschewski, 2017). Pengujian dengan kuisioner dilakukan kepada 50 responden yang terdiri dari 15 orang yang bekerja dibidang arsitektur serta kepada 35 orang dengan berbagai macam pekerjaan dengan rentang usia antara 15 tahun hingga 64 tahun. Komponenkomponen penyusun kuisioner terdiri dari beberapa pertanyaan-pertanyaan yang tertera pada Tabel 1 .

Tabel 1. Penilaian responden terhadap sistem

\begin{tabular}{|c|c|}
\hline No. & Pernyataan \\
\hline 1. & Sistem dapat berjalan baik dan efisien pada perangkat web. \\
\hline 2. & $\begin{array}{l}\text { Pengguna merasa nyaman dengan tampilan sistem yang } \\
\text { menarik. }\end{array}$ \\
\hline 3. & Alur kerja sistem yang sederhana dan mudah digunakan. \\
\hline 4. & $\begin{array}{l}\text { Sistem dapat memberikan respon yang baik dan jelas } \\
\text { terhadap input yang dimasukkan. }\end{array}$ \\
\hline 5. & $\begin{array}{l}\text { Hasil perhitungan, informasi maupun output dalam sistem } \\
\text { sederhana mudah dimengerti }\end{array}$ \\
\hline 6. & $\begin{array}{l}\text { Fitur perhitungan dan pemodelan dalam sistem membantu } \\
\text { pengguna dalam penerapan Asta Kosala-Kosali dengan } \\
\text { mudah dan menyenangkan. }\end{array}$ \\
\hline 7. & $\begin{array}{l}\text { Mendukung pengguna dalam Mempelajari Arsitektur } \\
\text { Tradisional Bali. }\end{array}$ \\
\hline 8. & Informasi yang terdapat dalam sistem bermanfaat. \\
\hline 9. & $\begin{array}{l}\text { Secara umum sistem sudah sesuai dengan ekspektasi dan } \\
\text { kebutuhan pengguna. }\end{array}$ \\
\hline 10. & $\begin{array}{l}\text { Sistem Informasi Rumah Tradisional Bali Berdasarkan Asta } \\
\text { Kosala-Kosali layak untuk dijadikan media pembelajaran } \\
\text { terkini dalam mempelajari Arsitektur Tradisional Bali. }\end{array}$ \\
\hline
\end{tabular}

Tabel 1 merupakan tabel penilaian responden terhadap sistem guna mengukur seberapa puas responden terhadap sistem. Responden memberikan rentang nilai 1 sampai 5 untuk setiap pertanyaan pada kuisioner. Hasil kuisioner kepuasan pengguna dapat dilihat pada Gambar 13.

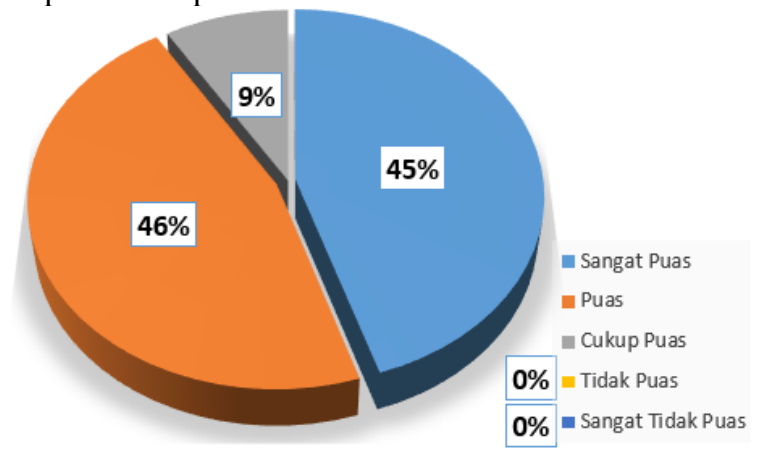

Gambar 13 Tingkat kepuasan pengguna terhadap sistem

Gambar 13 merupakan persentase hasil kuisioner tingkat kepuasan pengguna terhadap Sistem Informasi Asta Kosala-Kosali dan Asta Bumi dalam Arsitektur Rumah Tradisional Bali berbasis web. Dari 50 orang responden, terdapat $0 \%$ menyatakan sangat tidak puas dan tidak puas, $9 \%$ menyatakan cukup puas, $46 \%$ menyatakan puas, dan $45 \%$ menyatakan sangat puas sehingga didapat tingkat rata-rata kepuasan pengguna pada sistem sebesar $87,24 \%$.

\section{KESIMPULAN}

Kesimpulan dari hasil penelitian yang telah dicapai adalah Sistem Informasi Rumah Tradisional Bali Berdasarkan Asta Kosala-Kosali berbasis web dapat membantu dalam pengaplikasian aturanatauran Asta Kosala-Kosali yang terdapat pada fitur dalam sistem yaitu fitur menentukan arah rumah/lahan yang baik, menentukan letak pintu pekarangan yang baik, tata letak bangunan rumah yang baik, serta fitur dalam pembuatan sanggah pamerajan. Pemodelan 2 dimensi dan 3 dimensi yang disajikan dalam sistem dapat membantu memberikan gambaran bangunan rumah yang baik berdasarkan aturan Asta Kosala-Kosali dan Asta Bumi. Sistem dapat menjadi media pengenalan Arsitektur Tradisional Bali. Hal ini terbukti dari interpretasi dari hasil evaluasi terhadap 50 responden dari 10 pertanyaan yang diajukan dengan hasil rata-rata $87,6 \%$ kepuasan pengguna terhadap sistem. Sistem yang dirancang berbasis web menjadikan lebih mudah dijangkau dan diakses secara cepat dan real-time.

\section{SARAN}

Saran yang dapat diberikan baik pada ilmu pengetahuan maupun kepada masyarakat untuk pengembangan atau penelitian yang terkait, antara lain. 
1. Penelitian ini diharapkan dapat terus dikembangkan dengan menambah informasi yang lebih lengkap serta penambahan fitur-fitur baru pada sistem.

2. Pengembangan untuk penelitian selanjutnya yaitu sistem tidak hanya dapat diakses melalui web namun juga platform yang lain seperti mobile dan desktop.

\section{DAFTAR PUSTAKA}

ADIPUTRA, T., WIYONO, D. \& SARWADI, A. 2016. Konsep Hulu-Teben pada Permukiman Tradisional Bali Pegunungan / Bali Aga di Desa Adat Bayung Gede Kecamatan Kintamani Kabupaten Bangli , Bali. Jurnal Online Universitas Gadjah Mada. vol 37, no. 1: 14-31.

DAMAYANTI, S. 2017. The Undagi Lexicon in the Manufacture of Residential Houses Based on Asta Kosala Kosali Concept in Denpasar. RETORIKA: Jurnal Ilmu Bahasa. vol 3, no. 2: 290-296.

DWIJENDRA, A. 2008. Arsitektur Rumah Tradisional Bali.Edited by J. Atmaja.Udayana University Press.

INTARAN, I. G. P. B., KORIAWAN, G. E. H. \& WITARI, N. N. S. 2015. Kajian Visual Dapur Tradisional Khas Kecamatan Kubu Karangasem. Jurnal Pendidikan Seni Rupa Undiksha. vol 3, no. 1: 1-15.

PARWATA, I. W. 2011. Rumah Tinggal Tradisional Bali dari Aspek Budaya dan Antropometri. Jurnal Mudra. vol 26, no. 1: 95-106.

RUDIASTI, W., SUDANA, O. \& RAHARJA, S. 2017. Android based Introduction of Dewata Nawa Sanga Virtual Reality Application. International Journal of Computer Applications. vol 169, no. 7: 3845.

SAPUTRA, P. S., SUKARSA, I. M. \& BAYUPATI, I. P. A. 2017. Sistem Informasi Monitoring Perkembangan Anak di Sekolah Taman Kanak - kanak Berbasis Cloud. Lontar Komputer. vol 8, no. 2: 112-123.

SCHREPP, M., HINDERKS, A. AND THOMASCHEWSKI, J. 2017. Construction of a Benchmark for the User Experience Questionnaire ( UEQ ). International Journal of Interactive Multimedia and Artificial Intelligence. vol 4, no. 4: 40-44.

SUDANA, O., WULAN, S. \& WIRDIANI, N. K. A. 2016. Instructional Learning Media to Create Upakara for Nyiramin Layon Procession based on Android. International Journal of Computer Applications. vol 144, no. 10 : $32-35$.
SUHARTA, I. G. P., SUDIARTA, I. G. P. \& ASTAWA, W. P. 2017. Ethnomathematics of Balinese Traditional Houses. International Research Journal of Enginerering, IT \& Scientific Research (IRJEIS). vol 3, no. 4: 42-50.

UTAMI, Y., NUGROHO, A. \& WIJAYA, A. F. 2018. Perencanaan Strategis Sistem Informasi dan Teknologi Informasi pada Dinas Perindustrian dan Tenaga Kerja Kota Salatiga. Jurnal Teknologi Informasi dan Ilmu Komputer. vol 5, no. 3: 253-260.

WIARTIKA, dkk. 2013. Augmented Reality Book Sistem Rumah Tradisional Bali Berdasarkan Asta Kosala-Kosali. Jurnal Nasional Pendidikan Teknik Informatika (JANAPATI). vol 2, no. 3: 234-242.

WIJAYA, I. K. M. 2017. Perubahan Wujud AngkulAngkul Pada Rumah Tinggal Etnik Bali di Kota Denpasar. UNDAGI : Jurnal Ilmiah Arsitektur. vol 5, no. 2: 40-46.

WIRAWAN, I. P., BUANA, P. W. \& WIRANATHA, A. A. K. A. C. 2017. Rancang Bangun Game ' Mrajan Bali ' Sebagai Media Pembelajaran Berbasis Android. Merpati. vol 5, no. 1: 57-66. 
Halaman ini sengaja dikosongkan 